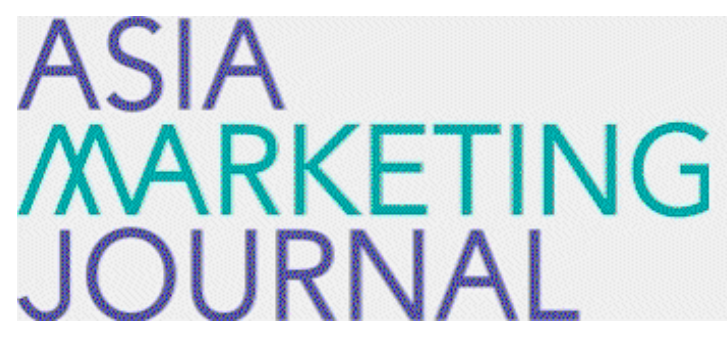

ASIA MARKETING JOURNAL

Volume 17 | Issue 3

Article 5

10-31-2015

\title{
Comparison of Experienced and Inexperienced Consumers' Utilisation of Extrinsic Cues in Product Evaluation
}

Yoonjeun Kim

Kiwan Park

Yaeri Kim

Chung

Follow this and additional works at: https://amj.kma.re.kr/journal

Part of the Marketing Commons

\section{Recommended Citation}

Kim, Yoonjeun; Park, Kiwan; Kim, Yaeri; and Chung (2015) "Comparison of Experienced and Inexperienced Consumers' Utilisation of Extrinsic Cues in Product Evaluation," Asia Marketing Journal: Vol. 17 : Iss. 3 , Article 5.

Available at: https://doi.org/10.15830/amj.2015.17.3.105

This Article is brought to you for free and open access by Asia Marketing Journal. It has been accepted for inclusion in Asia Marketing Journal by an authorized editor of Asia Marketing Journal. 


\title{
Comparison of Experienced and Inexperienced Consumers' Utilisation of Extrinsic Cues in Product Evaluation: Evidence from the Korean Fine Arts Market*
}

\author{
Yoonjeun Kim** \\ Kiwan Park ${ }^{* * *}$ \\ Yaeri $\mathrm{Kim}^{* * * *}$ \\ Youngmok Chung*****
}

This study compares experienced and inexperienced consumers' patterns in cue utilisation in product
evaluations in the arts market. Borrowing the notion of high- and low-scope cues introduced by the cue-diagnosticity framework, we differentiate between the two most readily discernible extrinsic cues in the fine arts market - an art gallery's brand reputation (a high-scope cue) and certificates of authenticity (a low-scope cue). These two cues are different in nature; the former is more abstract, intangible, and rich in content, so is more difficult to interpret than the latter. Given the differences in experienced and inexperienced consumers' information processing styles, we hypothesise that experienced arts consumers form perceived credibility of and purchase intentions towards artworks based on high-scope cues, whereas inexperienced consumers do so based on low-scope cues. To test our hypothesis, we conducted a consumer intercept study at Korea's two most representative art fairs. The survey participants were categorised into either experienced or inexperienced consumers based on their prior purchase experience, and their responses to a set of attribute combinations about two artworks created by the same artist were collected. The results indicate that experienced participants show higher purchase intentions when an art gallery's reputation is very high, whereas inexperienced participants show higher purchase intentions when artworks are accompanied by certificates of

\footnotetext{
* This research was supported by the Institute of Management Research at Seoul National University.

** Graduate Student, Interdisciplinary Program in Arts Management, Graduate School, Seoul National University, Korea (yoonjeunkim@gmail.com)

*** Associate Professor of Marketing, Graduate School of Business, Seoul National University, Korea (kiwanp@snu.ac.kr), Corresponding Author

**** Doctoral Student, Graduate School of Business, Seoul National University, Korea (yaerikim17@gmail.com), Corresponding Author

***** Head of Interdisciplinary Program in Arts Management, Graduate School, Seoul National University, Korea (mylove@snu.ac.kr)
} 
authenticity. This congruency effect between prior experience and cue type is mediated by the perceived credibility of the artworks. The findings suggest a correspondence between a consumer's prior experience and the types of extrinsic cues that are important in product evaluations. To the best of our knowledge, this study is the first attempt ever to investigate the role of prior experience in determining when to use high- or low-scope cues. It also provides a useful frame of reference to advise marketers on the effective sales approach based on a client's prior purchase experience.

Key words: art gallery's brand reputation, certificates of authenticity, cue diagnosticity, perceived credibility, prior purchase experience, purchase intention

\section{Introduction}

The arts market is a venue in which the more you know, the more you enjoy. This statement describes the importance of information in the arts market. It is very difficult for consumers to evaluate the value of artworks prior to purchasing them, due to their abstract characteristics. Consumers may not understand the aesthetic and financial value of artworks readily even when a certain piece of information is presented. Thus, cue utilisation is particularly important to consumers' quality judgments and purchase behavior in the arts market (Schönfeld and Reinstaller, 2005). Although previous researchers have extensively studied the effects of such factors as price, warranty, and brand reputation in product evaluation (e.g., Shimp and Bearden, 1982; Teas and Agarwal, 2000; Purohit and Srivastava, 2001), such studies are lacking in the arts market. Furthermore, little research has ever been conducted to investigate the rel- ative influences of diverse extrinsic cues in the arts market.

In this research, we investigate whether experienced and inexperienced consumers use different types of extrinsic cues in product evaluations in the arts market. In doing so, we differentiate two types of extrinsic cues, high- and low-scope cues, as introduced by the cue-diagnosticity framework (Purohit and Srivastava, 2001; Miyazaki et al., 2005). The two types of cues change over time differently (Purohit and Srivastava, 2001). Compared with transient lowscope cues, long-lasting high-scope cues evolve slowly through substantial effort. Thus, updating the valence of these cues from negative to positive calls for a considerable investment of time and money. Given their static nature, highscope cues are generally perceived as more credible and diagnostic than low-scope cues. Against this backdrop, we propose that experienced consumers rely more on high-scope cues, whereas inexperienced consumers rely more on low-scope cues. Those who are less experienced 
may lack the ability to be appreciative of highscope cues, whereas experienced consumers appreciate the value of high-scope cues very well. We investigate this rationale by conducting a consumer intercept study in the Korean fine arts market.

\section{Theory and Hypotheses}

\subsection{Characteristics of Artworks as Products}

Artworks are generally considered to be experience goods (English, 2013). Artworks such as novels, songs, films, and paintings must be experienced before they can be fully understood and appreciated. Their true quality may not be immediately obvious to consumers at the time of purchase, but may instead become more evident upon consumption. However, high-end cultural artworks such as the fine arts used as stimuli in this study can be considered to be credence goods (Darby and Karni, 1973). Consumers cannot easily judge the quality of these goods based on their experience alone; rather, they may depend on the judgment of certified authorities as a signal of credibility (Jahn et al., 2005).

The characteristics of artworks as experience and credence goods are inseparable from their characteristics as information goods, whose main value is derived from the quality of the in- formation they contain (Zorloni, 2013). Information asymmetry, which refers to the information gap between market participants who possess different quantities and qualities of information, tends to exist in markets that trade in information goods. When a seller's information is perfect but their consumer's information is limited, the market may be either non-existent or consist of only low-quality merchandise (Akerlof, 1970). The Korean arts market is a good example. Its characteristic opaqueness gives rise to a closed transaction system, characterised by non-disclosure of market information, uncertainty in the authentication and evaluation of artworks, and a consistently low record of sale and resale.

As both experience/credence and information goods, artworks may entail a high level of perceived risk for consumers (Mitra et al., 1999). Bauer (1960) defined perceived risk as the expectation of possible negative consequences from the purchase of a particular product or service. It refers to the consumer's experience of uncertainty with regard to the outcome of their purchase decisions. Thus, consumers attempt to reduce their degree of anxiety by becoming better informed and by seeking the recommendations of experts.

Marketers can use signaling to effectively solve these problems created by artwork traits. An agent with an information advantage shares his or her knowledge with other agents, so that consumers can be better informed about product quality (Spence, 1973). Arts marketers can 
provide extrinsic cues such as price, certificates of authenticity, and an art gallery's brand reputation as signals of quality (Shimp and Bearden 1982; Teas and Agarwal, 2000, Purohit and Srivastava, 2001). ${ }^{1)}$ Arts consumers can lower their perceived risk, ensure product quality, and establish credibility using these extrinsic cues (Schönfeld and Reinstaller, 2005).

\subsection{Art Gallery's Brand Reputation and Certificates of Authenticity as High- and Low-Scope Cues}

There are a variety of extrinsic cues, such as price (Kihlstrom and Riordan, 1984; Gerstner, 1985; Tellis and Wernerfelt, 1987; Boyle and Lathrop, 2009), warranty (Spence, 1977; Wiener, 1985; Kelley, 1988; Boulding and Kirmani, 1993; Lutz and Padmanabhan, 1995), guarantee (Moorthy and Srinivasan, 1995; Steiner and Yang, 2010), retailer reputation (Chu and Chu, 1994; Jones and Kim, 2010), and advertising (Rotfeld and Rotzoll, 1976; Milgrom and Roberts, 1986; Kirmani, 1990; Mizuno and Odagiri, 1990; Kirmani, 1997). In this research, we particularly focus on an art gallery's brand reputation as a high-scope cue and certificates of authenticity as a low-scope cue, because these cues can easily differentiate between experienced and inexperienced arts consumers in product evaluations. Experienced consumers, when making product evaluations, tend to place great weight on diagnostic cues such as an art gallery's brand reputation. They have the capacity to process information in a comprehensive and deep maner and make refined judgements on the basis of such cues (Maheswaran and Sternthal, 1990). Conversely, inexperienced consumers tend to base their judgments on salient and shallow cues such as product warranty, which may bias their subsequent information processing (Maheswaran, 1994).

We choose to use certificates of authenticity as a low-scope cue instead of using product warranty which has been heavily researched in the cue-diagnosticity framework (Purohit and Srivastava, 2001; Miyazaki et al., 2005; Taylor, 2009; Akdeniz et al., 2013; Roggeveen et al., 2014). Certificates of authenticity are very similar to warranty in nature and more relevant to the evaluations of artworks. Although no studies, to the best of our knowledge, have directly categorised certificates of authenticity as a low-scope cue, certificates of authenticity share with warranty the critical feature of $\mathrm{re}^{-}$ ducing potential risk in purchase decision (Kelly,

1) Certificates of authenticity are documents testifying to the authenticity of artworks. They are vouchers offered in conjunction with artworks as proof that they are authentic. They contain information such as the title of the artwork, the medium in which it is rendered, its size, date of creation, edition number (for limited edition prints) and various details of certification (such as the artist, gallery, dealer, and appraiser). In Korea, no official organisation is responsible for issuing such certificates. As with any other documentation, certification can easily be forged. Thus, it is essential for arts consumers to verify the origins of a certificate of authenticity. 
1996). Moreover, certificates of authenticity can be changed relatively easily and inexpensively (Purohit and Srivastava, 2001, p.125), compared to an art gallery's brand reputation.

Instead, art galleries can rely on their brand reputation to demonstrate that their goods are of premium quality. Reputation, which is a powerful indicator of a gallery's ability to choose artists with sound potential, is understood and appreciated by those with knowledge and experience in the field. The reputation of an art gallery is a high-scope cue that evolves as the gallery interacts with artists and consumers over time. Each decision to feature good artists in a variety of communications, such as art shows, media reviews, and other venues, sends signals of the gallery's recommendations to its consumers and of its commitment and trust to the artists. The heightened recognition due to the artists and the consumers' satisfaction with well-informed purchases in turn boosts the gallery's reputation and performance (Schönfeld and Reinstaller, 2005). Unfortunately, a high reputation is difficult to establish within a short period in the fine arts market, as artworks are traded somewhat infrequently and only in small quantities.

\subsection{Moderating Role of Prior Experience}

As discussed, extrinsic cues vary in their diagnostic value; high-scope cues are in general more credible and diagnostic in evaluating prod- ucts than low-scope cues (Purohit and Srivastava, 2001). We argue that the diagnosticity and credibility of high-scope cues are appreciated better by experienced than inexperienced consumers. The literature has found that consumers with great knowledge and experience rely more on diagnostic cues in product evaluation by constructing higher relative valuation differentials for differences in diagnostic cues than in nondiagnostic cues (Cordell, 1997). Consumer familiarity or expertise increases the importance of high-scope cues, such as brand, but decreases that of low-scope cues, such as origin labels on agri-food products (Chocarro et al., 2009). Thus, we predict that when evaluating artworks, experienced consumers will give more weight to an art gallery's brand reputation, whereas inexperienced consumers will give more weight to certificates of authenticity.

To support this prediction, we focus on two important differences between an art gallery's reputation and certificates of authenticity. First, an art gallery's brand reputation is built over a long period, so is more abstract, intangible, and multidimensional than certificates of authenticity (Keller, 2003). Experienced consumers tend to evaluate brands more favourably when they are presented with abstract rather than concrete information (Hong and Sternthal, 2010). Second, the signal ability of an art gallery's brand reputation versus certificates of authenticity may differ according to consumers' familiarity or experience. The concrete information in cer- 
tificates is less likely to vary in its signal content with the level of prior experience, whereas abstract brand information may be differently interpreted by experienced and inexperienced consumers. Inexperienced consumers may struggle to understand and appreciate the rich information contained in brand reputation (Price and Dawar, 2002).

These differences between the two cues have important implications for consumer information processing. According to the dual-processing models of attitudes and persuasion (Petty and Cacioppo, 1986; Chen and Chaiken, 1999), experienced consumers process information on broad and deep levels through more elaborate processing. They are good at understanding the significant meaning of high-scope cues, which is abstract, complicated, and rich in content. Furthermore, consumers with more familiarity and experience are more likely to use brand name as the basis for product evaluations as they structure their product-related knowledge around brand information, such as usage, advertising, and public relations (Bettman and Park, 1980). Conversely, inexperienced consumers develop less elaborate systems to process information in shallow and narrow terms. They give high weight to tangible, familiar low-scope cues that are easier to comprehend. Therefore, experienced consumers are able to judge the perceived diagnosticity of high-scope cues better than inexperienced consumers, thereby $\mathrm{re}^{-}$ lying more on such cues for product evalua- tions, whereas inexperienced consumers focus more on superfical low-scope cues that only assure safe decisions. We argue that the two groups of consumers' differential perceptions of cue diagnosticity affect credibilty of artworks first and purchase intentions subsequently.

To summarise, arts consumers rely on $\mathrm{ex}^{-}$ trinsic cues to tackle the problems created by the characteristics of artworks as experience/ credence and information goods. However, experienced and inexperienced consumers will show different patterns in cue utilisation (Raju, Lonial, and Mangold, 1995). Considering the inherent cue differences and the two groups of consumers' different processing styles, we propose that the two consumer groups will depend on different cues to assure the perceived credibility of artworks and subsequently to form purchase intentions (Figure 1). Thus, we hypothesise a congruency effect between cues and consumer groups as follows:
H 1a: Experienced consumers will show higher purchase intentions towards artworks with no certificate of authenticity and high gallery reputation than towards artworks with a certificate of authenticity and low gallery reputation.

H 1b: Inexperienced consumers will show higher purchase intentions towards artworks with a certificate of authenticity and low gallery reputation than towards artworks with no certificate of authenticity 
and high gallery reputation.

H2a: Experienced consumers will perceive the credibility of artworks with no certificate of authenticity and high gallery reputation as higher than of artworks with a certificate of authenticity and low gallery reputation.

$H$ 2b: Inexperienced consumers will perceive the credibility of artworks with a certificate of authenticity and low gallery reputation as higher than of artworks with no certificate of authenticity and high gallery reputation.

H3: The proposed congruency effect in H1 will be mediated by the perceived credibility of artworks.

\section{Empirical Study}

\subsection{Method}
3.1.1 Participants, research design, and stimuli

Two hundred participants were recruited for a survey from Korea's two most representative

〈Figure 1〉 Conceptual Model

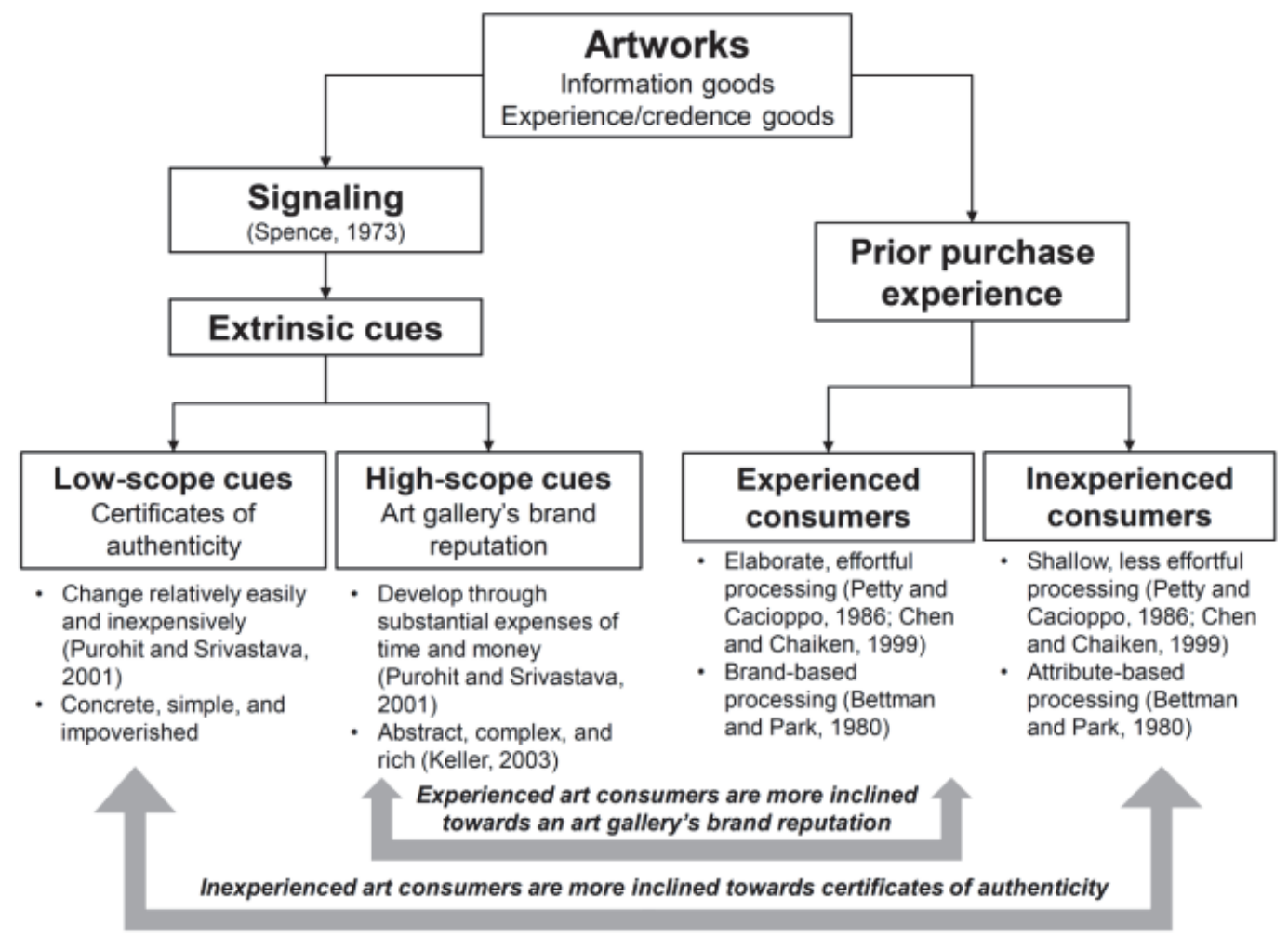

Comparison of Experienced and Inexperienced Consumers' Utilisation of Extrinsic Cues in Product Evaluation: Evidence from the Korean Fine Arts Market 111 
art fairs, KIAF (Korea International Art Fair) and MANIF (Manifestation d'art Nouveau International et Forum), both held from September to October in 2013 (MANIF: 9/28-10/6, KIAF: 10/3-10/7). We carried out this study as a quasi-experiment in which all the independent variables except for consumer type were manipulated (Campbell and Stanley, 1963). To be specific, before administering the survey, we first asked the participants about their past experiences with artwork purchase. If they ever had such an experience, then we classified them as experienced consumers. We continued our participants recruiting process until we collected one hundred participants for each of the experienced and inexperienced consumers. We tried to minimise the problem caused by self-selection by treating independent variables to be within-participants and controlling for inherent differences across the participants (Shadish, Cook, and Campbell, 2002).

Each of the participants completed a survey that, like in conjoint experiments, comprised 16 hypothetical cards. Eight cards depicted a painted piece and another eight cards depicted a printed piece, both created by Unsung Han, a renowned artist who works on both painting and printmaking. Each of the cards manipulated three product attributes, indicating whether the art gallery as a distributor of the artworks had a high or low brand reputation, whether a certificate of authenticity was present or absent, and whether the product price was high or low. As such, this study used a 2 (consumer type: inexperienced vs. experienced) $\times 2$ (art gallery's brand reputation: high vs. low) $\times 2$ (certificate of authenticity: present vs, absent) $\times 2$ (price: high vs. low) $\times 2$ (artwork type: painting vs. printmaking) mixed design. Consumer type was a between-participants factor, whereas the others were all within-participants factors.

To vary the art gallery's reputation, we selected one of the two art galleries - one real name (Gallery IHN) and one hypothetical name (Gallery $\mathrm{Li}$ ) - as the distributor of the artwork for each card. On the first page of the survey, we explicitly explained that the two galleries differed in brand recognition and reliability among the Korean arts consumers and in whether they were affiliated with the Galleries Association of Korea. In each card, the certificate of authenticity was described as either accompanying the artworks or not. The price level was varied by selecting two price points within a hypothetical but reasonably determined market price range. ${ }^{2)}$

On the first page of the survey, we presented general information on the fine arts

2) We decided not to describe the price information in detail because disclosing it was not permitted by the artist.

The painted piece was set at $7 \%$ higher or lower than the average of the minimum and maximum of the market price range. Similarly, the printed piece was set at $10 \%$ higher or lower than the average of the minimum and maximum of the market price range. 
market such as the definitions of painting and printmaking, the concept of certificates of authenticity, the differences described earlier between the two art galleries, and an introduction to the Galleries Association of Korea to familiarise the participants with the terms used in the study. We also presented them with a short artist biography and an explanation of the painted piece by Unsung Han, Pomegranate (Chung, 2011; see Appendix). After the painted piece was evaluated for eight different combinations of the three attributes, the stimulus was replaced with a printed piece by the same artist, Two Pomegranates (Chung, 2011; see Appendix). To reduce the extraneous effect of a budget, we asked the participants to imagine that they had enough money to purchase both products.

\subsubsection{Manipulation check}

Instead of including manipulation check measures in the main study, we used a manipulationcheck group (Kidd, 1976) whose sole purpose was to evaluate the efficacy of manipulations. We did so to avoid some well-kown problems associated with manipulation checks. For example, if manipulation check measures precede dependent variables, they may produce the problem of demand characteristics. Manipulation check measures, if administered after dependent variables, may not capture the efficacy of manipulations which often lead to a temporary change in independent variables (Perdue and Summers, 1986). Since the manipulation associated with certificates of authenticity was obvious in this study, an independent sample of forty participants responded to a question associated only with an art gallery's brand reputation: "I believe the reputation of this gallery is high" $(1=$ strongly disagree, 7 = strongly agree). The participants perceived Gallery IHN as a gallery of higher reputation than Gallery Li (5.00 vs. $3.05 ; F_{1,38}=17.33, P<0.001$ ).

\subsubsection{Dependent and ancillary measures}

The participants responded to two 7-point scales for the artwork on each card (16 in all). The scales measured the perceived credibility of the artwork $(1=$ not at all credible; $7=$ very credible: Moussa and Touzani, 2008) and the participant's purchase intentions $(1=$ very unlikely to purchase; 7 = very likely to purchase). We collected the participants' demographic information, such as gender, age, education, and income level.

\subsubsection{Analysis strategy}

We analysed the data using multiple regression. Of the four within-participants factors, we treated artwork type and price as blocking factors (i.e., categorical control variables) because these variables were not of interest in this study and their effects needed to be controlled for. 
The analysis model was:

purchase intention $=$ consumer type

+ gallery reputation + certificate of authenticity

+ consumer type $\times$ gallery reputation

+ consumer type $\times$ certificate of authenticity

+ gallery reputation $\times$ certificate of authenticity

+ consumer type $\times$ gallery reputation $\times$

certificate of authenticity

+ artwork type + price, where all of the predictors were contrastcoded variables that were -1 for inexperienced consumer, low reputation, certificate present, printed piece, and low price, and +1 otherwise. We analysed the model using the SAS GLM Procedure.

\subsection{Results}

Table 1 summarises the sample characteristics. The sample consisted of slightly more men

〈Table 1〉 Sample Characteristics

\begin{tabular}{|c|c|c|c|c|c|}
\hline \multirow[b]{2}{*}{ Variables } & & \multicolumn{2}{|c|}{$\begin{array}{c}\text { Total } \\
(n=200)\end{array}$} & \multirow{2}{*}{$\begin{array}{c}\begin{array}{c}\text { Experienced } \\
(n=100)\end{array} \\
\mathrm{N} \text { or } \%\end{array}$} & \multirow{2}{*}{$\begin{array}{c}\text { Inexperienced } \\
(n=100) \\
\mathrm{N} \text { or } \%\end{array}$} \\
\hline & & $\mathrm{N}$ & $\%$ & & \\
\hline \multirow[t]{2}{*}{ Gender } & Male & 113 & 56.5 & 55 & 58 \\
\hline & Female & 87 & 43.5 & 45 & 42 \\
\hline \multirow[t]{6}{*}{ Age } & $20-29$ & 28 & 14.0 & 3 & 25 \\
\hline & 30-39 & 79 & 39.5 & 21 & 58 \\
\hline & $40-49$ & 46 & 23.0 & 29 & 17 \\
\hline & $50-59$ & 35 & 17.5 & 35 & 0 \\
\hline & $60-69$ & 11 & 5.5 & 11 & 0 \\
\hline & $\geq 70$ & 1 & 0.5 & 1 & 0 \\
\hline \multirow[t]{5}{*}{ Education } & High school & 4 & 2.0 & 4 & 0 \\
\hline & Bachelor's degree & 149 & 74.5 & 56 & 93 \\
\hline & Current in graduate school & 2 & 1.0 & 1 & 1 \\
\hline & Master's degree & 26 & 13.0 & 22 & 4 \\
\hline & Doctoral degree & 19 & 9.5 & 17 & 2 \\
\hline \multirow{7}{*}{$\begin{array}{l}\text { Household } \\
\text { income } \\
\text { (unit: }(11,000)^{\mathrm{a}}\end{array}$} & $\leq 30,000$ & 3 & 1.5 & 3 & 0 \\
\hline & $30,000-60,000$ & 46 & 23.0 & 15 & 31 \\
\hline & $60,000-90,000$ & 82 & 41.0 & 30 & 52 \\
\hline & $90,000-150,000$ & 35 & 17.5 & 24 & 11 \\
\hline & $150,000-200,000$ & 16 & 8.0 & 11 & 5 \\
\hline & $200,000-250,000$ & 6 & 3.0 & 5 & 1 \\
\hline & $\geq 250,000$ & 12 & 6.0 & 12 & 0 \\
\hline
\end{tabular}

SD, standard deviation. 
than women (56.5\% vs. $43.5 \%)$ and included more participants in their 20s and 30s than other age groups. The majority of the participants had completed at least a bachelor's degree and had a greater household income than the average Korean household (the GDP per capita in 2013 was \$26,200). The experienced and inexperienced consumer groups differed significantly in the distributions of age $\left(x^{2}{ }_{(5)}\right.$ $=84.75, P<0.0001)$, education $\left(\chi^{2}(4)=37.49\right.$, $P<0.0001)$, and income $\left(\chi^{2}(6)=36.21, P<\right.$ 0.0001 ). There was no significant difference in the distribution of gender $\left(\chi_{(1)}^{2}=0.18, P=\right.$ $0.67)$.

\subsubsection{Purchase intention}

The overall regression model was significant $\left(F_{9,3190}=1,206.32, P<0.0001\right.$; Table 2$)$. The result of the greatest interest was that the consumer type $\times$ gallery reputation $\times$ certificate interaction was significant $\left(F_{1,3190}=23.84\right.$, $P<0.0001)$. To understand this three-way interaction, we divided the sample into experienced and inexperienced consumers and conducted multiple regressions for each sub-sample (Table 3). As multiple within-participants factors were included, we created a dummycoded participants variable and entered it with the other variables of interest. This dummycoded variable corrected for extraneous effects attributable to individual differences by grouping all of the observations about each participant into one category (Pedhazur, 1982).

The results indicated that the relative influences of gallery reputation and certificate presence differed between experienced and inexperienced consumers. The purchase intentions of experienced consumers was influenced by gallery reputation $($ estimate $=1.15, P<0.0001)$

〈Table 2〉 Multiple Regression Analysis Results

\begin{tabular}{lrrr}
\hline \multicolumn{1}{c}{ Predictors } & d.f. & \multicolumn{1}{c}{ F } & $P$ \\
\hline Consumer type & 1 & 14.60 & $<0.0001$ \\
Gallery reputation & 1 & $4,914.29$ & $<0.0001$ \\
Certificate & 1 & $5,521.32$ & $<0.0001$ \\
Consumer type $\times$ gallery reputation & 1 & 60.38 & $<0.0001$ \\
Consumer type $\times$ certificate & 1 & 294.26 & $<0.0001$ \\
Gallery reputation $\times$ certificate & 1 & 0.02 & 0.8986 \\
Consumer type $\times$ gallery reputation $\times$ certificate & 1 & 23.84 & $<0.0001$ \\
Artwork type & 1 & 10.14 & 0.0015 \\
Price & 1 & 18.03 & $<0.0001$ \\
Error & 3,190 & & \\
\hline
\end{tabular}

Dependent variable: Purchase intention.

Regression model: $F_{9,3190}=1,206.32, P<0.0001$. 
〈Table 3〉 Multiple Regression Analysis Results by Consumer Type

\begin{tabular}{|c|c|c|c|c|c|}
\hline Predictors & Estimate & $\mathrm{SE}$ & d.f. & $\mathrm{F}$ & $P$ \\
\hline \multicolumn{6}{|c|}{ Experienced consumers } \\
\hline Participant & & & 99 & 4.11 & $<0.0001$ \\
\hline Gallery reputation & 1.15 & 0.02 & 1 & $4,273.25$ & $<0.0001$ \\
\hline Certificate & 0.84 & 0.02 & 1 & $2,301.70$ & $<0.0001$ \\
\hline Gallery reputation $\times$ certificate & 0.07 & 0.02 & 1 & 15.94 & $<0.0001$ \\
\hline Artwork type & 0.10 & 0.02 & 1 & 30.13 & $<0.0001$ \\
\hline Price & 0.43 & 0.02 & 1 & 590.92 & $<0.0001$ \\
\hline Error & & & 1,495 & & \\
\hline \multicolumn{6}{|c|}{ Inexperienced consumers } \\
\hline Participant & & & 99 & 2.44 & $<0.0001$ \\
\hline Gallery reputation & 0.92 & 0.02 & 1 & $2,768.80$ & $<0.0001$ \\
\hline Certificate & 1.35 & 0.02 & 1 & $5,961.15$ & $<0.0001$ \\
\hline Gallery reputation $\times$ certificate & -0.07 & 0.02 & 1 & 17.89 & $<0.0001$ \\
\hline Artwork type & -0.00 & 0.02 & 1 & 0.02 & 0.8860 \\
\hline Price & -0.30 & 0.02 & 1 & 298.49 & $<0.0001$ \\
\hline Error & & & 1,495 & & \\
\hline
\end{tabular}

Dependent variable: Purchase intention.

$\mathrm{SE}$, standard error.

more than certificate presence (estimate $=0.84$, $P<0.0001$ ), whereas inexperienced consumers were influenced by certificate presence (estimate $=1.35, P<0.0001)$ more than gallery reputation (estimate $=0.92, P<0.0001$ ). Furthermore, the gallery reputation $\times$ certificate interaction had opposite directions in the experienced (estimate $=0.07, P<0.0001$ ) and inexperienced (estimate $=-0.07, P<0.0001)$ groups.

To test hypothesis 1 directly, we recoded gallery reputation and certificate variables to determine whether the positivity of the two cues matched or mismatched (see Table 4 and
Figure 2). We generated four types of cues: high gallery reputation without a certificate, low reputation with a certificate, high reputation with a certificate, and low reputation without a certificate. The first two types represented inconsistent cues, whereas the latter two represented consistent cues. Then we conducted contrast analyses by focusing on the two types of inconsistent cues. The results indicated that purchase intentions were more heavily influenced by different cues depending on consumer type. The experienced consumers showed higher purchase intentions towards the artworks with 
〈Figure 2〉 Purchase Intentions as a Function of Cue Type and Consumer Type
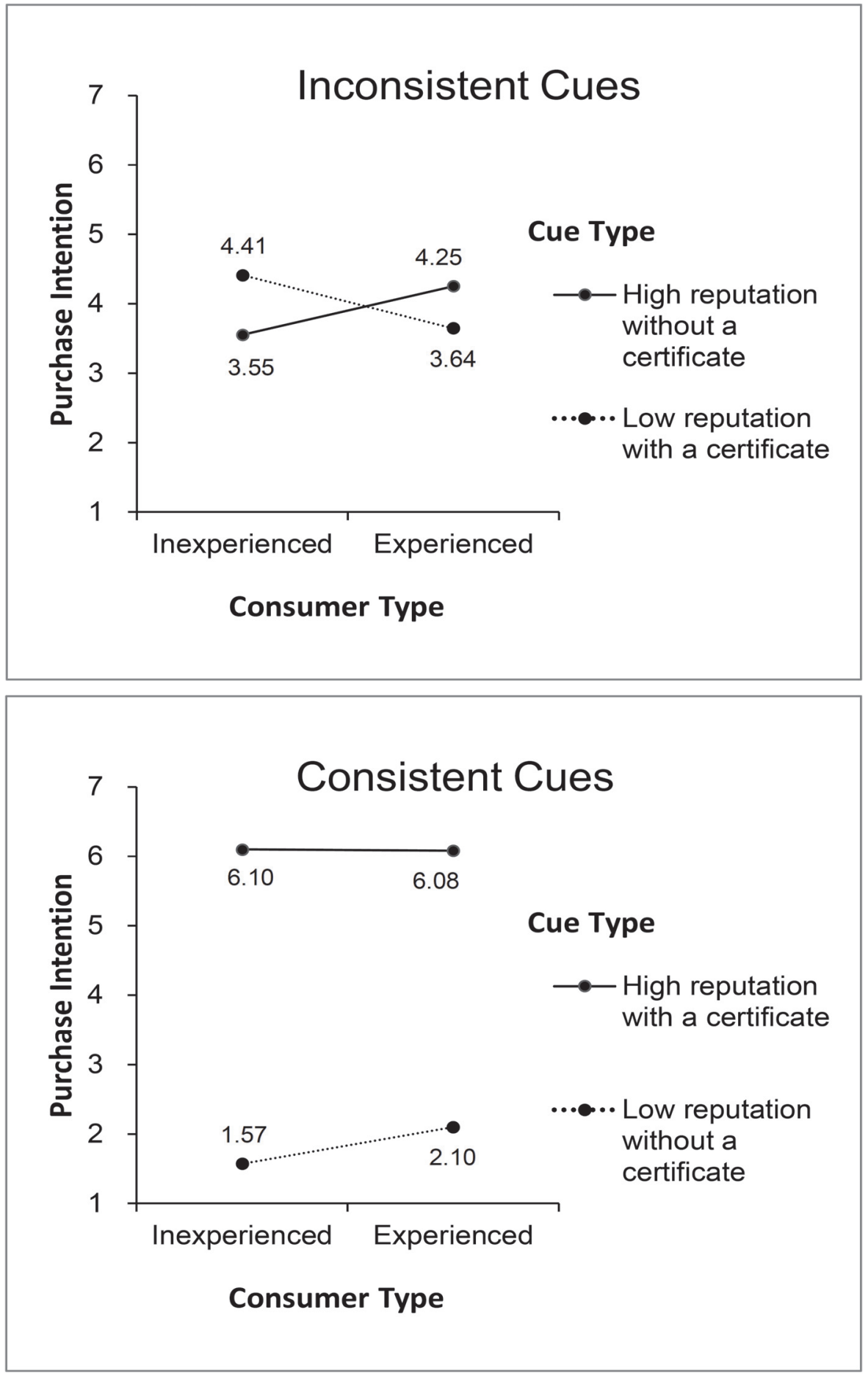
no certificate and high gallery reputation than towards the artworks with a certificate and low gallery reputation (4.25 vs. $3.64 ; F_{1,3190}$ $=107.34, P<0.0001)$. In contrast, the inexperienced consumers showed higher purchase intentions towards the artworks with a certificate and low gallery reputation than towards the artworks with no certificate and high gallery reputation (4.41 vs. 3.55; $F_{1,3190}=212.11$, $P<0.0001)$. These results supported hypothesis 1. For the two types of consistent cues, both experienced (6.08 vs. 2.10; $F_{1,3190}=$ 4,557.86, $P<0.0001)$ and inexperienced $(6.10$ vs. $\left.1.57 ; F_{1,3190}=5,912.94, P<0.0001\right)$ con- $^{-}$

〈Table 4〉 Purchase Intention and Perceived Credibility in Two Conditions of Inconsistent Cues

\begin{tabular}{ccccc}
\hline \multirow{2}{*}{$\begin{array}{c}\text { Dependent } \\
\text { variables }\end{array}$} & \multicolumn{2}{c}{$\begin{array}{c}\text { High reputation } \\
\text { without a certificate }\end{array}$} & \multicolumn{2}{c}{$\begin{array}{c}\text { Low reputation } \\
\text { with a certificate }\end{array}$} \\
\cline { 2 - 5 } & $\begin{array}{c}\text { Experienced } \\
\text { consumers }\end{array}$ & $\begin{array}{c}\text { Inexperienced } \\
\text { consumers }\end{array}$ & $\begin{array}{c}\text { Experienced } \\
\text { consumers }\end{array}$ & $\begin{array}{c}\text { Inexperienced } \\
\text { consumers }\end{array}$ \\
\cline { 2 - 5 } & $M(\mathrm{SD})$ & $M(\mathrm{SD})$ & $M(\mathrm{SD})$ & $M(\mathrm{SD})$ \\
\hline Purchase intention & $4.25(0.92)$ & $3.55(0.92)$ & $3.64(0.95)$ & $4.14(0.90)$ \\
Perceived credibility & $4.37(0.95)$ & $3.67(0.97)$ & $3.77(0.91)$ & $4.52(0.83)$ \\
\hline
\end{tabular}

SD, standard deviation.

〈Table 5〉 Mediation by Perceived Credibility

\begin{tabular}{|c|c|c|c|c|c|c|c|c|c|}
\hline & \multicolumn{9}{|c|}{ Dependent variables } \\
\hline & \multicolumn{3}{|c|}{$\frac{\text { Regression 1 }}{\text { Purchase intention [Y] }}$} & \multicolumn{3}{|c|}{$\frac{\text { Regression } 2}{\text { Perceived credibility [M] }}$} & \multicolumn{3}{|c|}{$\frac{\text { Regression 3 }}{\text { Purchase intention }}[\mathrm{Y}]$} \\
\hline & Estimate & SE & $P$ & Estimate & SE & $P$ & Estimate & SE & $P$ \\
\hline Intercept & 3.96 & 0.02 & $\langle 0.0001$ & 4.08 & 0.02 & $\langle 0.0001$ & 0.94 & 0.09 & $<0.0001$ \\
\hline Cue type $[X]$ & -0.06 & 0.02 & 0.0070 & -0.06 & 0.02 & 0.0019 & -0.02 & 0.02 & 0.3723 \\
\hline Consumer type [W] & -0.02 & 0.02 & 0.4954 & -0.01 & 0.02 & 0.5759 & -0.01 & 0.02 & 0.6755 \\
\hline Cue type $\times$ consumer type & 0.37 & 0.02 & $<0.0001$ & 0.36 & 0.02 & $<0.0001$ & 0.10 & 0.02 & $<0.0001$ \\
\hline Perceived credibility [M] & - & - & - & - & - & - & 0.74 & 0.02 & $<0.0001$ \\
\hline Artwork type & 0.05 & 0.02 & 0.0466 & 0.01 & 0.02 & 0.5343 & 0.04 & 0.02 & 0.0370 \\
\hline Price & 0.07 & 0.02 & 0.0014 & 0.44 & 0.02 & $<0.0001$ & -0.25 & 0.02 & $<0.0001$ \\
\hline Regression model & $F_{5,1594}=$ & $\begin{array}{r}55.65, \\
=0 .\end{array}$ & $P<0.0001$ & $\begin{array}{r}F_{5,1594}= \\
R^{2}\end{array}$ & $\begin{array}{l}1.37, F \\
=0.336\end{array}$ & $1<0.0001$ & $F_{6,1593}=$ & $\begin{array}{l}74.38, \\
=0.5\end{array}$ & $\begin{array}{l}<<0.0001 \\
2\end{array}$ \\
\hline
\end{tabular}

Cue type $[1=$ high reputation without a certificate vs. $-1=$ low reputation with a certificate].

Consumer type $[1=$ experienced vs. $-1=$ inexperienced $]$.

$\mathrm{X}=$ independent variable, $\mathrm{W}=$ moderator, $\mathrm{M}=$ mediator, and $\mathrm{Y}=$ criterion variable.

$\mathrm{SE}$, standard error. 
sumers showed higher purchase intentions towards the artworks with a certificate and high gallery reputation than towards the artworks with no certificate and low gallery reputation.

\subsubsection{Mediation via perceived credibility}

Focusing only on the two types of inconsistent cues, we tested the relationships predicted in hypotheses 2 and 3 jointly using the PROCESS macro (model 8; Hayes 2013; Hayes and Preacher 2013). The hypotheses represented a mediated moderation, in that the effect of cue type (i.e., high reputation without a certificate vs. low reputation with a certificate) on purchase intention was moderated by consumer type, and this moderation was mediated by perceived credibility.

The results indicated that the effect of the cue type $\times$ consumer type interaction on purchase intentions was indeed mediated by perceived credibility (Tables 4 and 5). The overall indirect effect of the interaction on purchase intentions via perceived credibility was significant ( point estimate $=0.53,95 \% \mathrm{CI}=[0.4719$, 0.5967]). The conditional indirect effects via perceived credibility were significant for both experienced ( point estimate $=0.22,95 \% \mathrm{CI}=$ $[0.1797,0.2620])$ and inexperienced (point estimate $=-0.31,95 \% \mathrm{CI}=[-0.3580,-0.2703])$ consumers.

\section{General Discussion and Conclusion}

This study offers an empirical analysis of how two types of extrinsic cues interact with consumers' prior experience in product evaluation for artworks characterised as information and experience/credence goods. We confirm that experienced arts consumers are more heavily influenced by high-scope cues, such as an art gallery's brand reputation, whereas inexperienced arts consumers are more heavily influenced by low-scope cues, such as certificates of authenticity. Our results also corroborate mediation by the perceived credibility of the artworks.

To the best of our knowledge, this is the first attempt to understand the role of prior experience as a determinant of which extrinsic cues are used. Although Bao et al. (2011) investigated how two consumer characteristics, product familiarity and risk aversion, moderated the effects of two high-scope cues, store image and product signatureness (i.e., the degree to which a product category is associated with a particular store), no individual-level moderators have yet been proposed to determine when to give more weight to high- or low-scope cues for product evaluation.

According to the cue-diagnosticity framework (Feldman and Lynch, 1988; Purohit and Srivastava, 2001; Miyazaki et al., 2005), a signature feature of high-scope cues is that their 
diagnosticity is not influenced much by the presence and diagnosticity of other cues. Conversely, the relative diagnosticity of low-scope cues tends to vary depending on the presence of high-scope cues in the environment. The presence of positive high-scope cues is less likely to deliver a false signal, rendering accompanying low-scope cues relatively more diagnostic, whereas negative high-scope cues will render other lowscope cue less diagnostic. This argument suggests an interaction between high- and lowscope cues in determining the perception of quality and product evaluation, as empirically corroborated in the literature (e.g., Purohit and Srivastava, 2001; Khare et al., 2011; Akdeniz et al., 2013).

However, our findings indicate that the benefit from certificates of authenticity was not moderated by an art gallery's brand reputation. Inexperienced consumers rated artworks with certificates favourably even when the art galleries involved had low reputations. This result seems to be driven by the fact that inexperienced consumers cannot grasp the deeper meaning of low gallery reputation for artworks and thus tend to ignore the influence of the cue for judgments. In previous research, brand reputation has been manipulated to be easily comprehended without great product knowledge and experience (e.g., Purohit and Srivastava, 2001). As such, the literature has not explicitly considered the effect of consumer experience in cue utilisation. We believe that this novel find- ing makes an important contribution by identifying consumer experience as a boundary condition for an interaction between high- and low-scope cues. However, future research is called for to confirm that the observed effect of prior experience may also occur for other credence products.

One limitation of this study is that the customers were categorised based simply on their purchase experience. We believe that our operationalisation of prior experience is valid and meaningful because product-related experience is an important determinant of subjective knowledge (Park et al., 1994) and expertise and familiarity have very similar effects on how much importance consumers place on extrinsic cues when choosing products (Chocarro et al., 2009). Nonetheless, future research is still needed to investigate the influences of different consumer knowledge measures.

Another limitation is that this study included multiple within-participants factors and for the stimuli used two similar artworks created by the same artist. We addressed some of the problems generated by the repeated measures by including the participants variable to account for idiosyncratic differences. Although the findings confirm relative differences across conditions effectively, we believe that adopting betweenparticipants designs in future research would be beneficial to tackling such problems as carryover effects and participants fatigue. Moreover, expanding the nature and number of artworks 
used as stimuli would further enhance the generalisability of the findings.

Although our conceptualisation of an art gallery's reputation and certificates of authenticity is based on the cue-diagnosticity framework, there are many inherent differences between the two cues which cannot be easily captured by the notion of cue scope. As we argued, the two cues have different abstractness and signaling abilities. In addition, certificates are an assurance of an artwork's authentication, so pertain more to risk reduction, whereas an art gallery's reputation is more indicative of the quality of its artworks (Price and Dawar, 2002). Considering multiple differences inherent to the distinction between high- and low-scope cues, as exemplified by an art gallery's reputation and certificates of authenticity, the robustness and generalisability of our findings can be increased by testing other high- and low-scope cues. For example, the volume of word-of-mouth communications as a high-scope cue can be tested to generalise our findings (Khare et al., 2011).

Finally, while we confirm mediation via perceived credibility of artworks, we cannot discount the presence of other possible mediating variables. The most promising one is perceived diagnosticity of extrinsic cues for quality judgments (Feldman and Lynch, 1988). By introducing this variable as a mediator, we could directly test the validity of the cue-diagnosticity framework (Purohit and Srivastava, 2001;
Miyazaki et al., 2005), which we draw upon to establish our research hypotheses. Alternatively, the intervening processes that underlie the observed effects can be captured by using other independent and/or moderating variables. If the observed effects are indeed due to fundamental differences in complexity and richness between high- and low-scope cues, manipulating cognitive motivation as an indepent variable (Petty and Cacioppo, 1986) or measuring need for cognition (Cacioppo and Petty, 1982) may serve as an indirect method to make inference about the underlying processes.

This research offers significant managerial implications for a gallery's sales strategy. Given that different types of consumers react differently to extrinsic cues, an effective approach to sales would be based on clients' prior experience. The fact that experienced consumers choose to reference brand reputation suggests that trust should be built with consumers by continuously interacting through a variety of media such as art shows, personalised consulting service, and provision of exclusive information. More importantly, since brand reputation signals not only reliability but also performance of products, art galleries need to consistently discover talented artists whose artworks can exhibit high aesthetic and financial values in the long term. With such brand-building efforts, art galleries can forge long-standing relationships with their consumers.

In contrast, the finding that inexperienced 
consumers rely more on certificates of authenticity which signal nothing more than reliability implies that they are unable to adequately judge the quality of artworks and thus, have high sensitivity to potential purchase risks. Art galleries should thus compensate for their incompetence in judging quality by providing certificates of authenticity and expert third party opinions and guarantees to help them to avoid taking risks and make safe choices. This strategy is particularly important for galleries that are late entries to a market and have not yet established a good reputation. On the other hand, as inexperienced consumers accumulate more experiences over time, art galleries may want to provide detailed information increasingly to facilitate consumers' understanding of their high reputation and the importance of reputation information in artworks evaluation. Then consumers can access a broader and deeper range of information with which they reduce their perceived risk of making a poor selection. To conclude, it is essential for arts marketers to vary their approach according to consumer groups they are targeting. This research provides a useful frame of reference when targeting potential consumers in the arts market.

〈Received March 11. 2015〉

$\langle$ Revised October 14. 2015〉

〈Accepted November 2. 2015〉

\section{References}

Akdeniz, B., Calantone, R. J., and Voorhees, C. M. (2013), "Effectiveness of marketing cues on consumer perceptions of quality: The moderating roles of brand reputation and third-party information," Psychology \& Marketing, 30(1), 76-89.

Akerlof, G. A. (1970), "The market for "lemons": quality uncertainty and the market mechanism," Quarterly Journal of Economics, 84(3), 488-500.

Bao, Y., Sheng, S., Bao, Y., and Stewart, D. (2011), “Assessing quality perception of private labels: Intransient cues and consumer characteristics," Journal of Consumer Marketing, 28(6), 448-458.

Bauer, R. A. (1960), "Consumer behavior as risk taking," In Risk Taking and Information Handling in Consumer Behavior (ed. by D.F. Cox), pp. 389-398, Harvard University Press, Cambridge, MA, USA.

Bettman, J. R. and Park, C. W. (1980), "Effects of prior knowledge and experience and phase of the choice process on consumer decision processes: A protocol analysis," Journal of Consumer Research, 7(3), 234-248. Boulding, W. and Kirmani, A. (1993), “A consumer-side experimental examination of signaling theory: Do consumers perceive warranties as signals of quality?" Journal of Consumer Research, 20(1), 111-123. 
Boyle, P. J. and Lathrop, E. S. (2009), “Are consumers' perceptions of price-quality relationships well calibrated?" International Journal of Consumer Studies, 33(1), 58-63.

Cacioppo, J. T. and Petty, R. E. (1982), "The need for cognition," Journal of Personality and Social Psychology, 42(1), 116-131.

Campbell, D. T. and Stanley, J. C. (1963), Experimental and Quasi-Experimental Designs for Research. Houghton Mifflin, Boston, MA, USA.

Chen, S. and Chaiken, S. (1999), "The heuristicsystematic model in its broader context," In Dual-Process Theories in Social Psychology (ed. by S. Chaiken \& Y. Trope), pp. 73-96. The Guilford Press, New York, NY, USA.

Chocarro, R., Cortiñas, M., and Elorz, M. (2009), "The impact of product category knowledge on consumer use of extrinsic cues - a study involving agrifood products," Food Quality and Preference, 20(3), 176-186.

Chu, W. and Chu, W. (1994), "Signaling quality by selling through a reputable retailer: An example of renting the reputation of another agent," Marketing Science, 13(2), 177-189.

Chung, Y. (2011) Unsung Han. Seoul National University Press, Seoul, Korea.

Cohen, J., Cohen, P., West, S. G., and Aiken, L. S. (2013), Applied Multiple Regression/ Correlation Analysis for the Behavioral Sciences, 3rd edn. Routledge, London, UK. Cordell, V. V. (1997), "Consumer knowledge measures as predictors in product evaluation," Psychology \& Marketing; 14(3), 241-260. Darby, M. R. and Karni, E. (1973), "Free competition and the optimal amount of fraud," Journal of Law and Economics, 16(1), 67-88. English, J. F. (2013), "The economics of cultural awards," In Handbook of the Economics of Art and Culture (ed. by V. A. Ginsburgh \& D. Throsby), pp. 119-144. Elsevier, San Diego, CA, USA.

Feldman, J. M. and Lynch, J. G. (1988), "Selfgenerated validity and other effects of measurement on belief, attitude, intention, and behavior," Journal of Applied Psychology, 73(3), 421-435.

Gerstner, E. (1985), "Do higher prices signal higher quality?" Journal of Marketing Research, 22(2), 209-215.

Hayes, A. F. (2013), Introduction to Mediation, Moderation, and Conditional Process Analysis: A Regression-Based Approach, Guilford Press, New York, NY, USA.

Hayes, A. F. and Preacher, K. J. (2013), "Conditional process modeling: Using structural equation modeling to examine contingent causal processes," In Structural Equation Modeling: A Second Course (ed. by G. R. Hancock \& R. O. Mueller), pp. 219-266. Information Age Publishing, Greenwich, CT, USA.

Hong, J. and Sternthal, B. (2010), "The effects of consumer prior knowledge and processing strategies on judgments," Journal of Mar- 
keting Research, 47(2), 301-311.

Jahn, G., Schramm, M., and Spiller, A. (2005), "The reliability of certification: Quality labels as a consumer policy tool," Journal of Consumer Policy, 28(1), 53-73.

Jones, C. and Kim, S. (2010), "Influences of retail brand trust, off-line patronage, clothing involvement and website quality on online apparel shopping intention," International Journal of Consumer Studies, 34(6), 627-637.

Keller, K. L. (2003), "Brand synthesis: The multidimensionality of brand knowledge," Journal of Consumer Research, 29(4), 595600.

Kelley, C. A. (1996), "Warranty and consumer behavior: Product choice," In Product Warranty Handbook (ed. by W. R. Blischke \& D. N. P. Murthy), pp. 409-419. Marcel Dekker, New York, NY, USA.

(1988), "An investigation of consumer product warranties as market signals of product reliability," Journal of the Academy of Marketing Science, 16(2), 72-78.

Khare, A., Labrecque, L. I., and Asare, A. K. (2011), "The assimilative and contrastive effects of word-of-mouth volume: An experimental examination of online consumer ratings," Journal of Retailing, 87(1), 111-126.

Kidd, R. F. (1976), "Manipulation checks: Advantage or disadvantage?" Representative Research in Social Psychology, 7(2), 160-165.

Kihlstrom, R. E. and Riordan, M. H. (1984), "Advertising as a signal," Journal of Poli- tical Economy, 92(3), 427-450.

Kirmani, A. (1990), "The effect of perceived advertising costs on brand perceptions," Journal of Consumer Research, 17(2), 160-171. (1997), “Advertising repetition as a signal of quality: If it's advertised so much, something must be wrong," Journal of Advertising, 26(3), 77-86.

Lutz, N. A. and Padmanabhan, V. (1995), "Why do we observe minimal warranties?" Marketing Science, 14(4), 417-441.

Maheswaran, D. (1994), "Country of origin as a stereotype: Effects of consumer expertise and attribute strength on product evaluations," Journal of Consumer Research, 21(2), 354365.

Maheswaran, D. and Sternthal, B. (1990), "The effects of knowledge, motivation, and type of message on ad processing and product judgments," Journal of consumer Research, 17(1), 66-73.

Milgrom, P. and Roberts, J. (1986), "Price and advertising signals of product quality," Journal of Political Economy, 94(4), 796-821. Mitra, K., Reiss, M. C., and Capella, L. M. (1999), “An examination of perceived risk, information search and behavioral intentions in search, experience and credence services," Journal of Services Marketing, 13(3), 208228.

Miyazaki, A. D., Grewal, D., and Goodstein, R. C. (2005), "The effect of multiple extrinsic cues on quality perceptions: a matter of 
consistency," Journal of Consumer Research, 32(1), 146-153.

Mizuno, M. and Odagiri, H. (1990), "Does advertising mislead consumers to buy lowquality products?" International Journal of Industrial Organization, 8(4), 545-558.

Moorthy, S. and Srinivasan, K. (1995), "Signaling quality with a money-back guarantee: The role of transaction costs," Marketing Science, 14(4), 442-466.

Moussa, S. and Touzani, M. (2008), "The perceived credibility of quality labels: A scale validation with refinement," International Journal of Consumer Studies, 32(5), 526-533.

Park, C. W., Mothersbaugh, D. L., and Feick, L. (1994), "Consumer knowledge assessment," Journal of Consumer Research, 21(1), 71-82. Pedhazur, E. J. (1982), Multiple Regression in Behavioral Research: Explanation and Prediction, 2nd edn. Rinehart, Holt, \& Winston, Fort Worth, TX, USA.

Perdue, B. C. and Summers, J. O. (1986), "Checking the success of manipulations in marketing experiments," Journal of Marketing Research, 23(4), 317-326.

Petty, R. E. and Cacioppo, J. T. (1986), "The elaboration likelihood model of persuasion," Advances in Experimental Social Psychology, 19, 123-205.

Price, L. J. and Dawar, N. (2002), "The joint effects of brands and warranties in signaling new product quality," Journal of Economic Psychology, 23(2), 165-190.
Purohit, D. and Srivastava, J. (2001), "Effect of manufacturer reputation, retailer reputation, and product warranty on consumer judgments of product quality: A cue diagnosticity framework," Journal of Consumer Psychology, 10(3), 123-134.

Raju, P., Lonial, S., and Mangold, W. (1995), "Differential effects of subjective knowledge, objective knowledge, and usage experience on decision making: an exploratory investigation," Journal of Consumer Psychology, 4(2), 153-180.

Roggeveen, A. L., Goodstein, R. C., and Grewal, D. (2014), "Improving the effect of guarantees: The role of a retailer's reputation," Journal of Retailing, 90(1), 27-39.

Rotfeld, H. J. and Rotzoll, K. B. (1976), "Advertising and product quality: Are heavily advertised products better?" Journal of Consumer Affairs, 10(1), 33-47.

Shadish, W. R., Cook, T. D., and Campbell, D. T. (2002), Experimental and Quasi-experimental Designs for Generalized Causal Inference, Wadsworth Cengage Learning, Boston, MA, USA.

Schönfeld, S. and Reinstaller, A. (2005), "The effects of gallery and artist reputation on prices in the primary market for art: A note," Vienna University of Economics and Business Working Paper Series, 90, 1-13.

Shimp, T. A. and Bearden, W. O. (1982), "Warranty and other extrinsic cue effects on consumers' risk perceptions," Journal of 
Consumer Research, 9(1), 38-46.

Spence, M. (1973), “Job market signaling,” Quarterly Journal of Economics, 87(3), 355-374. (1977), "Consumer misperceptions, product failure and producer liability," $R e^{-}$ view of Economic Studies, 44(3), 561-572. Steiner, B. E. and Yang, J. (2010), "How do U.S. and Canadian consumers value credence attributes associated with beef labels after the North American BSE crisis of 2003?" International Journal of Consumer Studies, 34(4), 449-463.

Taylor, V. A. (2009), "Brand name and price cue effects within a brand extension context," Academy of Marketing Studies Journal, 13(2), 59-75.
Teas, R. K. and Agarwal, S. (2000), "The effects of extrinsic product cues on consumers' perceptions of quality, sacrifice, and value," Journal of the Academy of Marketing Science, 28(2), 278-290.

Tellis, G. J. and Wernerfelt, B. (1987), "Competitive price and quality under asymmetric information," Marketing Science, 6(3), 240253.

Wiener, J. L. (1985), “Are warranties accurate signals of product reliability?" Journal of Consumer Research, 12(2), 245-250.

Zorloni, A. (2013), The Economics of Contemporary Art: Markets, Strategies and Stardom, Springer-Verlag, Berlin, Germany. 
〈Appendix〉 Artworks Used in the Survey (Chung, 2011)

Painting

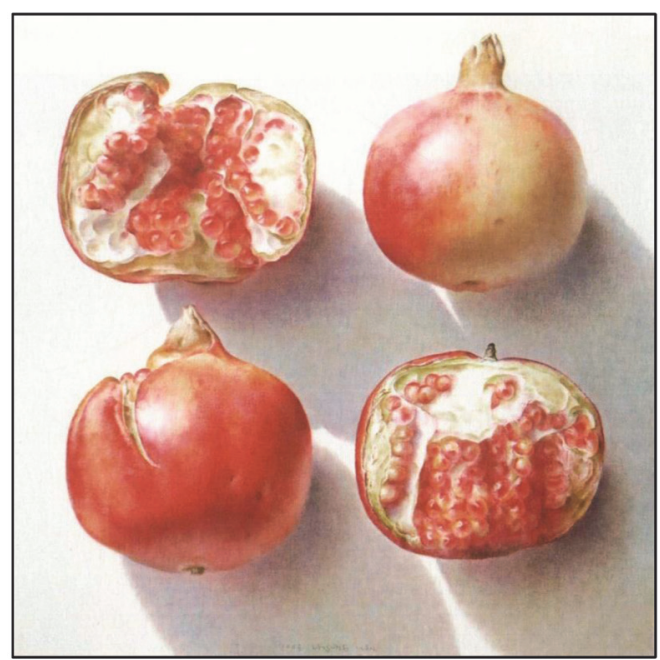

Unsung Han, Pomegranate, 2008

Oil on Canvas, $100 \times 100 \mathrm{~cm}$
Printmaking

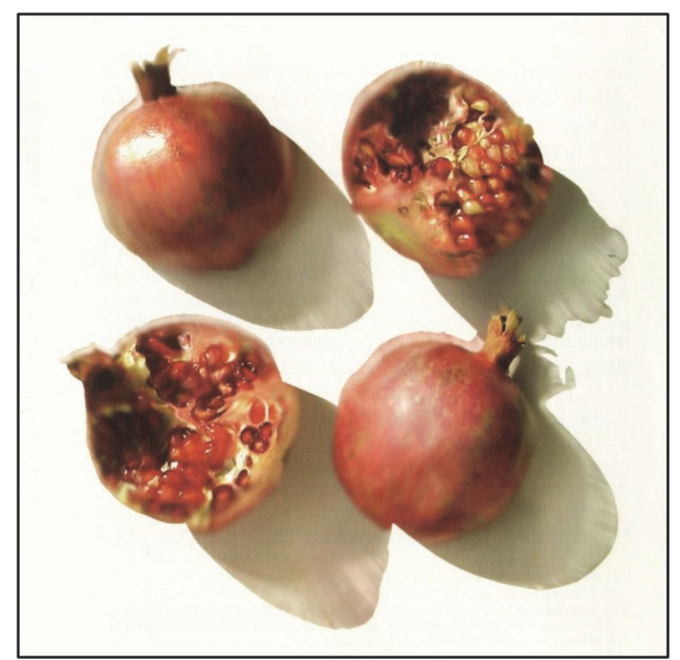

Unsung Han, Two Pomegranates, 2007

Digital C Print, $56 \times 56 \mathrm{~cm}$

Ed. of 30, AP. 10 